\title{
The effects of sulodexide on both clinical and molecular parameters in patients with mixed arterial and venous ulcers of lower limbs
}

This article was published in the following Dove Press journal:

Drug Design, Development and Therapy

13 May 2014

Number of times this article has been viewed

\author{
Raffaele Serra ${ }^{1,2, *}$ \\ Luca Gallelli,** \\ Angela Conti' \\ Giovanni De Caridi ${ }^{4}$ \\ Mafalda Massara ${ }^{4}$ \\ Francesco Spinelli ${ }^{4}$ \\ Gianluca Buffone' \\ Francesco Giuseppe Caliò ${ }^{5}$ \\ Bruno Amato 6 \\ Simona Ceglia ${ }^{7}$ \\ Giuseppe Spaziano8 \\ Luca Scaramuzzino 9 \\ Alessia Giovanna Ferrarese ${ }^{10}$ \\ Raffaele Grande' \\ Stefano de Franciscis ${ }^{1,2}$ \\ 'Interuniversity Center of Phlebolymphology \\ (CIFL), International Research and Educational \\ Program in Clinical and Experimental \\ Biotechnology, University Magna Graecia \\ of Catanzaro, Catanzaro, Italy; ${ }^{2}$ Department \\ of Medical and Surgical Sciences, University \\ Magna Graecia of Catanzaro, Catanzaro, Italy; \\ ${ }^{3}$ Department of Health Sciences, University \\ Magna Graecia of Catanzaro, Catanzaro, Italy; \\ ${ }^{4}$ Cardiovascular and Thoracic Department, \\ University of Messina, Messina, Italy; ${ }^{5}$ Unit of \\ Vascular Surgery, S Anna Hospital, Catanzaro, \\ Italy; ${ }^{6}$ Department of Clinical Medicine and \\ Surgery, University of Naples Federico II, Naples, \\ Italy; ${ }^{7}$ Department of Experimental and Clinical \\ Medicine, University Magna Graecia of Catanzaro, \\ Catanzaro, Italy; ${ }^{8}$ Department of Experimental \\ Medicine, Second University of Naples, Naples, \\ Italy; 'University Campus BioMedico of Rome, \\ Rome, Italy; ${ }^{10}$ Department of General Surgery, \\ University of Turin, Turin, Italy \\ *These authors contributed equally to \\ this work
}

Correspondence: Raffaele Serra

Department of Medical and Surgical

Sciences, University Magna Graecia

of Catanzaro, Viale Europa,

Germaneto 88100, Catanzaro, Italy

$\mathrm{Tel}+3909613647380 ; \mathrm{mob}+393387078043$

Fax +3909613647175

Email rserra@unicz.it
Background: Mixed venous and arterial ulcers account for approximately $15 \%-30 \%$ of all venous leg ulcerations. Several studies have shown that matrix metalloproteinases (MMPs) and neutrophil gelatinase-associated lipocalin (NGAL) play a central role in the pathophysiology of venous and arterial diseases. Some studies have shown the efficacy of glycosaminoglycans, such as sulodexide (SDX), in treating patients with leg ulcers. The aim of this study was to evaluate clinical effects of SDX and its correlation with MMPs and NGAL expression in patients with mixed arterial and venous leg ulcers.

Methods: Patients eligible for this study were of both sexes, older than 20 years, and with a clinical and instrumental diagnosis of mixed ulcer.

Results: Fifty-three patients of both sexes were enrolled and divided into two groups by means of randomization tables. Group A (treated group) comprised 18 females and ten males (median age: 68.7 years) treated with standard treatment (compression therapy and surgery) + SDX (600 lipoprotein lipase-releasing units/day intramuscularly) for 15 days followed by SDX 250 lipasereleasing units every 12 hours day orally for 6 months as adjunctive treatment. Group B (control group) comprised 17 females and eight males (median age: 64.2 years) treated with standard treatment only (compression therapy and surgery). The type of surgery was chosen according to anatomical level of vein incompetence: superficial venous open surgery and/or subfascial endoscopic perforating surgery. In all enrolled patients, blood samples were collected in order to evaluate the plasma levels of MMPs and NGAL through enzyme-linked immunosorbent assay. These results were compared to another control group (Group C) of healthy individuals. Moreover, biopsies of ulcers were taken to evaluate the tissue expression of MMPs and NGAL through Western blot analysis. Our results revealed that SDX treatment is able to reduce both plasma levels and tissue expression of MMPs improving the clinical conditions in patients with mixed ulcers.

Conclusion: Inhibition of MMPs could represent a possible therapeutic intervention to limit the progression of leg ulceration. In particular, our findings demonstrate the efficacy of SDX in patients with mixed arterial and venous chronic ulcers of the lower limbs.

Keywords: mixed ulcer, arterial ulcer, metalloproteinases, neutrophil gelatinase-associated lipocalin

\section{Introduction}

Chronic ulceration of the lower limbs is a serious clinical condition that induces pain and loss of limb function along with an impairment of quality of life and an increase in health care costs. ${ }^{1,2}$ In Western countries, the incidence of ulceration is rising in the population due to an increase in both life expectancy and risk factors for atherosclerotic stenosis, ie, smoking, obesity, and diabetes. ${ }^{3-5}$ Chronic venous ulceration (CVU), 
the pathophysiologic evolution of chronic venous disease, affects $1 \%$ of the adult population and is associated with a marked decrease in the quality of life and an increase in economic burden. ${ }^{6-8}$ Around $15 \%-30 \%$ of patients with CVU have signs of arterial impairment presenting with a reduced ankle-brachial pressure index ([ABPI] lower than 0.8)..$^{9-12}$ Mixed ulcers are characterized by edema, eczema, hyperkeratotic skin, maceration, inadequate presence of granulation tissue, rolled wound edges, and delayed healing. ${ }^{12,13}$ The biomolecular substrate of these manifestations is the change in both structure and function of the extracellular matrix (ECM). ECM is a network of interlacing macromolecules that forms a supporting structure for vascular wall and skin integrity and is maintained by the action of matrix metalloproteinases (MMPs) (which degrade ECM proteins) and their inhibitors (tissue inhibitors of MMPs). ${ }^{14}$

Several studies have shown that MMPs play a central role in the pathophysiology of venous and arterial diseases ${ }^{15-26}$ and in related diseases. ${ }^{27}$ Neutrophil gelatinase-associated lipocalin (NGAL) is a protein belonging to the lipocalin family and is expressed by activated neutrophils. NGAL has the ability to positively modulate the activity of MMP-9 in particular, by forming the NGAL/MMP-9 complex, protecting MMP-9 from proteolytic degradation. Inhibition of MMPs could represent a possible therapeutic intervention to limit the progression of leg ulceration. In particular, some authors have documented the efficacy of glycosaminoglycans in patients with chronic ulcers of the lower limbs. ${ }^{28,29}$ The term "glycosaminoglycan" refers to a category of related molecules that share common biologic properties, including heparin, low-molecular-weight heparin, heparan sulfate, and mixed glycosaminoglycan formulations, such as sulodexide (SDX). In particular, the role of SDX in vascular disease and its inhibitory effect on the proteolytic activity has been reported. ${ }^{30-34}$

The aim of this study was to evaluate clinical effects of SDX and its correlation with MMPs and NGAL expression in patients with mixed arterial and venous leg ulcers.

\section{Materials and methods Study design}

We performed an open-label, parallel-groups study, which was conducted between January 2010 and December 2012 in four clinical departments (Catanzaro 1, Catanzaro 2, Messina, and Naples) and with prior approval from the investigational review board of CIFL at University Magna Graecia of Catanzaro, in accordance with the Declaration of Helsinki. Before the beginning of the study, all participants provided written informed consent. In all patients, at the time of admission, the medical history was recorded and clinical examination, laboratory findings, and duplex ultrasonography were performed. During debridement, biopsies of the ulcers were taken and frozen $\left(-80^{\circ} \mathrm{C}\right)$ for Western blot evaluation of MMPs and NGAL expression.

Venous diseases were classified according to Clinical, Etiology, Anatomy, Pathophysiology (CEAP) classification. ${ }^{35}$ Superficial and deep vein systems and severity of venous reflux by duplex ultrasound and computed hemodynamic mapping were evaluated, as previously described. ${ }^{36,37}$ Arterial diseases were classified according to the ABPI: ${ }^{38}$ normal arteries (ABPI $>0.80)$; moderate arterial disease $(0.5<\mathrm{ABPI}<0.85)$; and severe arterial disease (ABPI $<0.5)$.

\section{Patients}

Patients eligible for this study were of both sexes, older than 20 years, with a clinical and instrumental diagnosis of mixed ulcer, presence of venous reflux flow, ABPI $>0.5$ and $<0.8$, ulcer duration $>6$ weeks, ulcer size $2.5-10 \mathrm{~cm}^{2}$, and $>50 \%$ granulation tissue on the wound bed.

Patients were excluded for the presence of diabetes mellitus; rheumatoid arthritis; malignancy; blood disorders; systemic disease; no current episode of ulceration; wound infection; ABPI $<0.5$ (patients with severe arterial disease at presentation were considered for arterial imaging with a view to revascularization) or $>0.8$; systolic ankle pressure $<60 \mathrm{mmHg}$; presence of necrotic tissue on the wound bed; use of medications that may impair wound healing; pain at rest; sensory loss (neuropathy); cardiac insufficiency; and medial calcinosis.

\section{Healing evaluation}

The healing was assessed in agreement with previous studies. ${ }^{16,20}$ Briefly, healing was calculated by means of computed planimetry at T1 and T2 of the study compared to initial measurement at $\mathrm{T} 0$. The result was divided by the number of weeks that the patient has been observed to obtain the total area healed per week.

For wound healing evaluation, we considered as rapid-healing ulcers those with a healing speed rate $\geq 1 \mathrm{~cm}^{2} /$ week and slow-healing ulcers those with a healing speed rate $<1 \mathrm{~cm}^{2} /$ week.

\section{Experimental protocol}

Blood samples were collected at the time of admission (T0) and 1 month (T1), 3 months (T2), and 6 months later (T3) in all enrolled patients, in order to evaluate plasma levels of 
MMPs and NGAL through enzyme-linked immunosorbent assay (ELISA). Moreover, at the time of surgery, biopsies of ulcers were taken to evaluate the expression of MMPs and NGAL through Western blot analysis.

\section{ELISA test}

In order to evaluate plasma MMPs and NGAL levels, blood samples were collected at the time of the admission in accordance with our previous studies. ${ }^{20-26}$

ELISA testing was performed with a commercially available generic ELISA kit (EMD Millipore, Billerica, MA, USA), using anti-MMP-2, MMP-8, MMP-9, and anti-NGAL monoclonal antibodies (monoclonal antibody kit against activated form of MMPs; EMD Millipore) that recognized only activated MMPs.

For both MMPs and NGAL, the results were evaluated with respect to a control group without ulcers.

\section{Western blot evaluation}

Wounds were biopsied at the time of the surgery (T1) under a $1 \%$ lidocaine local anesthesia and with full sterile precautions. The biopsy was made at a point equidistant from the center and edge of the ulcer. Our experience with biopsies in these patients indicates that the biopsy is well tolerated by the subject and does not influence healing outcomes in venous ulcers. Biopsy was immediately placed into a sterile collection container and sent for quantitative (microbiology) culture.

The biopsies obtained at the time of wound bed preparation (T1 and T2) were lysed for Western blot analysis in $2 \mathrm{~mL}$ of tissue protein extraction reagent $(25 \mathrm{mM}$ Bicine, $150 \mathrm{mM}$ sodium chloride, $\mathrm{pH}$ 7.6; Thermo Fisher Scientific, Waltham, MA, USA). The extracts were stored at $-80^{\circ} \mathrm{C}$.

Immunoblotting was performed using anti-MMP-2, MMP-8, MMP-9, and anti-NGAL monoclonal antibodies (monoclonal antibody kit against activated form of MMPs; Millipore Corporation) that recognized only activated MMPs and NGAL, and results have been expressed as arbitrary units, as recently described. ${ }^{20-26}$ All experiments were performed in triplicate.

\section{Quality of life measurement}

The EQ-5D ${ }^{\mathrm{TM}}$ questionnaire ${ }^{39,40}$ was used in order to measure health outcomes and quality of life of study patients.

\section{Statistical analysis}

All data are expressed as mean \pm standard error of the mean. Student's $t$-test was performed in order to analyze the difference between each group and the control. Analysis of variance (ANOVA) was used to evaluate the differences among the groups. Differences identified by ANOVA were pinpointed by unpaired Student's $t$-test. The threshold of statistical significance was set at $P<0.05$. SPSS software (version 21.0; IBM Corporation, Armonk, NY, USA) was used for the statistical analyses.

We defined this study as exploratory, therefore we did not determine a power calculation. In this light, the results can only be labeled as exploratory.

\section{Results \\ Patients}

During the study period, 53 patients of both sexes were enrolled and divided into two groups by means of randomization tables.

- Group A (treated group) comprised 18 females and ten males (median age: 68.7 years) with mixed ulcers and evidence of venous reflux at duplex scanning, treated with standard treatment + SDX (600 lipoprotein lipase-releasing units [LRUs]/ day intramuscularly) for 15 days followed by SDX 250 LRU every 12 hours orally for 6 months as adjunctive treatment.

- Group B (control group) comprised 17 females and eight males (median age: 64.2 years) with mixed ulcers treated with standard treatment only.

All patients were subjected to the most appropriate surgical treatment (defined as standard treatment), considering also the patient's wishes. The type of surgery, when it was accepted, was chosen according to anatomical level of vein incompetence: superficial venous surgery (Cure Conservatrice et Haemodinamique de l'Insuffisance Veineuse en Ambulatorie [CHIVA] procedure was used for the correction of superficial venous reflux) and/or subfascial endoscopic perforating surgery after computed hemodynamic mapping, as previously described. ${ }^{15-17,20-22,36,37}$

All patients received the application of a multicomponent, multilayer, compression bandage with pressure of 20-30 mmHg.

Patient characteristics are reported in Table 1.

\section{Wound healing}

Our results revealed a nonsignificant difference between groups A and B in both median ulcer area and mean area heal/week at admission (T1). In contrast, at the end of the treatment (T2), we documented a significant improvement in 
Table I Patient characteristics

\begin{tabular}{lll}
\hline Characteristic & Group A & Group B \\
\hline Age range, years & $48-82$ & $48-87$ \\
Median age, years & 68.7 & 64.2 \\
Sex & $10(35.7)$ & $8(32)$ \\
$\quad$ Male, $\mathrm{n}(\%)$ & $18(64.28)$ & $17(68)$ \\
$\quad$ Female, $\mathrm{n}(\%)$ & $15(53.57)$ & $13(52)$ \\
Family history of venous disease, $\mathrm{n}(\%)$ & & \\
Venous insufficiency, $\mathrm{n}(\%)$ & $19(67.86)$ & $16(64)$ \\
Superficial, $\mathrm{n}(\%)$ & $9(32.14)$ & $9(36)$ \\
Superficial and deep, $\mathrm{n}(\%)$ & $13(46.42)$ & $20(80)$ \\
Overweight (BMI 25-29.9 kg/m²), $\mathrm{n}(\%)$ & $5(17.86)$ & $2(8)$ \\
Obesity (BMI $\left.\geq 30 \mathrm{~kg} / \mathrm{m}^{2}\right), \mathrm{n}(\%)$ & $18(64.29)$ & $19(76)$ \\
Smoking, $\mathrm{n}(\%)$ & & \\
Arterial hypertension, $\mathrm{n}(\%)$ & $25(89.28)$ & $23(92)$ \\
Dyslipidemia, $\mathrm{n}(\%)$ & $16(57.14)$ & $1 \mathrm{I}(44)$ \\
0.5< ABPI $<0.85$ & $28(100)$ & $25(100)$ \\
Arterial disease, $\mathrm{n}(\%)$ & $18(64.28)$ & $17(68)$ \\
lleofemoral, $\mathrm{n}(\%)$ & $10(35.7)$ & $8(32)$ \\
Femoropopliteal, $\mathrm{n}(\%)$ & & \\
Claudication, $\mathrm{n}(\%)$ & $9(32.14)$ & $10(40)$ \\
Walking distance $>200 \mathrm{~m}$ & $19(67.86)$ & $15(60)$ \\
Walking distance $<200 \mathrm{~m}$ & 5.72 & 6.60 \\
Ulcer area, cm ${ }^{2}$ & $28(100)$ & $25(100)$ \\
Total patients, $\mathrm{n}(\%)$ & & \\
\hline
\end{tabular}

Notes: Group A: patients treated with sulodexide. Group B: patients without sulodexide.

Abbreviations: $\mathrm{ABPI}$, ankle-brachial pressure index; $\mathrm{BMI}$, body mass index.

wound healing in Group A with respect to Group B $(P<0.01)$ (Table 2).

\section{MMPs and NGAL plasma evaluation}

Using ELISA testing, we documented significantly higher levels $(P<0.01)$ of plasma MMP-2, MMP-8, MMP-9, and NGAL in wound patients (Group A and $\mathrm{B}$ ) with respect to control patients (Group C) (data not shown).

Group C consisted of 14 healthy volunteer patients (seven male and seven female, age range 50-80 years, median age: 66 years). In these patients, blood samples were taken in order to evaluate through the ELISA test both MMPs and NGAL values (Table 3).

We detected significantly lower levels of MMP-2, MMP-9, NGAL, and MMP-8 in patients treated with SDX

Table 2 Healing of mixed ulcers

\begin{tabular}{lll}
\hline & Group A & Group B \\
\hline $\begin{array}{l}\text { Median ulcer area }\left(\mathrm{cm}^{2}\right) \\
\text { for each time point }\end{array}$ & $5.08(\mathrm{TI}) ; 3.34(\mathrm{~T} 2)$ & $6.25(\mathrm{TI}) ; 5.18(\mathrm{~T} 2)$ \\
$\begin{array}{l}\text { Mean area heal/week } \\
\left(\mathrm{cm}^{2} / \text { week }\right)\end{array}$ & $\mathrm{I} .10(\mathrm{TI}) ; 1.2(\mathrm{~T} 2)$ & $0.87(\mathrm{TI}) ; 0.75(\mathrm{~T} 2)$ \\
\hline
\end{tabular}

Notes: Group A: patients treated with sulodexide. Group B: patients without sulodexide. TI: I month after admission. T2: 3 months after admission.
(Group A) with respect to untreated patients (Group B), with a time-dependent pattern (Table 4).

\section{MMPs and NGAL tissue expression}

Western blot analysis showed a lower expression of MMP2, MMP-9, NGAL, $(P<0.01)$, and MMP-8 $(P<0.05)$ in patients treated with SDX, with respect to untreated patients (Figure 1).

\section{Quality of life}

Quality of life was significantly higher for Group A (treated group) patients than for those in Group B (control group) (Figures 2 and 3 ) in the following areas of investigation: pain/discomfort; anxiety/depression; mobility; self care; usual activities.

\section{Discussion}

In this study, we evaluated the effects of SDX on clinical and biomolecular parameters in patients with mixed arterial and venous chronic leg ulcers.

Studies have shown that the majority of leg ulcers are associated with venous disease (estimates range from $40 \%$ $80 \%$ ), since other risk factors, including immobility, obesity, trauma, arterial disease, vasculitis, diabetes, and neoplasia, may also be present. ${ }^{41,42}$

Mixed ulcers have the features of CVU in combination with signs of arterial impairment; therefore, diagnosis of mixed ulcers is crucial because CVU is best managed using multilayer graduated compression bandaging, ${ }^{43,44}$ while compression is not appropriate for mixed ulcers ${ }^{45}$ because it may cause deterioration of tissue vitality and limb loss. ${ }^{46}$ However, recent studies have shown that compression therapy from 20-30 $\mathrm{mmHg}$ can improve arterial perfusion and venous function in patients with ABPI between 0.5 and 0.8 and support the ulcer healing. ${ }^{13,47}$

As previously described, ${ }^{8,15,19-26}$ the pathophysiological processes that characterize chronic ulcer onset are the activation of immune system cells and the secretion of specific protease enzymes known as MMPs. Previously, we documented that MMPs are involved in several vascular diseases. $^{48}$

In the present study, we have documented that MMP-2, MMP-8, MMP-9, and NGAL were strongly expressed in patients with mixed wound etiology with respect to the control Group C. Recently, several authors reported the involvement of MMPs in venous ulcers ${ }^{26,49,50}$ and their association with NGAL values..$^{20,51}$ In the present study, we documented higher levels of NGAL in patients with mixed ulcer that could 
Table 3 ELISA test evaluation of MMPs, at different times, in patients with CVUs treated (Group A) or not (Group B) with sulodexide for 6 months (end of study)

\begin{tabular}{|c|c|c|c|c|c|c|c|c|}
\hline & \multicolumn{2}{|l|}{ MMP-2 } & \multicolumn{2}{|l|}{ MMP-8 } & \multicolumn{2}{|l|}{ MMP-9 } & \multicolumn{2}{|l|}{ NGAL } \\
\hline & Group A & Group B & Group A & Group B & Group A & Group B & Group A & Group B \\
\hline & Mean \pm SEM & Mean \pm SEM & Mean \pm SEM & Mean \pm SEM & Mean \pm SEM & Mean \pm SEM & Mean \pm SEM & Mean \pm SEM \\
\hline T0 & $645.4 \pm 18$ & $649.8 \pm 19.3$ & $2.4 I \pm 0.15$ & $2.45 \pm 0.15$ & $177.7 \pm 4.8$ & $172.2 \pm 5.2$ & $172.3 \pm 4.6$ & $178.3 \pm 4.8$ \\
\hline TI & $591.2 \pm 16.5$ & $634.6 \pm 20.2$ & $2.21 \pm 0.13$ & $2.35 \pm 0.12$ & $138.7 \pm 5.7$ & $158.2 \pm 5.6$ & $137.8 \pm 5.7$ & $155.3 \pm 5.4$ \\
\hline T2 & $520.9 \pm 13.1$ & $594.4 \pm 20.4$ & $1.76 \pm 0.1$ & $2.01 \pm 0.11$ & $71.1 \pm 2.6$ & $97 \pm 3$ & $76.7 \pm 3.5$ & $138.7 \pm 4.9$ \\
\hline T3 & $478.3 \pm 15.6$ & $517.7 \pm 12.9$ & $1.46 \pm 0.08$ & $1.78 \pm 0.11$ & $43.4 \pm 1.7$ & $62.4 \pm 3.8$ & $62.4 \pm 3.5$ & $115.4 \pm 3.3$ \\
\hline
\end{tabular}

Notes: T0: admission; TI: I month later; T2: 3 months later; T3: 6 months later.

Abbreviations: CVU, chronic venous ulceration; ELISA, enzyme-linked immunosorbent assay; MMP, matrix metalloproteinase; NGAL, neutrophil gelatinase-associated lipocalin; SEM, standard error of the mean.

justify the severity of mixed vascular pathology observed in our study group. NGAL is a $25 \mathrm{kDa}$ protein stored in the granules of human neutrophils and released during the activation of these cells. NGAL positively modulates the activity of MMP-9, forming the NGAL/MMP-9 complex and protecting, in this way, MMP-9 from proteolytic degradation. Another important result is the high concentration of MMP-8, the predominant collagenase present in normal healing wounds. Overexpression and activation of this collagenase may be involved in the pathogenesis of non-healing chronic leg ulcers. ${ }^{22,52}$

The current results confirm the chronic nature of mixed ulcers and their tendency to slow down the normal healing processes. Recently, we and others documented in CVU patients that treatment with doxycycline as well as with a new nutraceutical substance modifying plasma MMP values improved both clinical symptoms and healing of ulcers. ${ }^{51-53}$

Evaluating the inflammatory nature of mixed ulcers and the involvement of MMPs in the physiopathology of these ulcers, it has been suggested that some drugs mimicking the action of endogenous tissue inhibitors of MMPs may be used in the treatment of venous and arterial diseases, including mixed ulcers. ${ }^{28-31,54-56}$ In particular, Mannello et al ${ }^{32}$ documented that SDX is able to inhibit the MMP-9 gelatinase secretion and activity. SDX is a highly purified mixture of

Table 4 Paired samples t-test evaluation of plasma MMP levels in patients treated (Group A) or not (Group B) with sulodexide

\begin{tabular}{|c|c|c|c|c|c|c|}
\hline & \multicolumn{4}{|l|}{ MMP-8 } & \multirow[t]{3}{*}{$t$} & \multirow{3}{*}{$\begin{array}{l}\text { Significance } \\
\text { (two-tailed) }\end{array}$} \\
\hline & \multirow[t]{2}{*}{ Mean } & \multirow[t]{2}{*}{ SEM } & \multicolumn{2}{|l|}{$95 \% \mathrm{Cl}$} & & \\
\hline & & & Lower & Upper & & \\
\hline \multicolumn{7}{|l|}{ MMP-8 } \\
\hline T0 A vs B & 0.00 & 0.04 & -0.9 & 0.09 & 0.00 & I \\
\hline TI A vs B & -0.9 & 0.5 & -0.2 & 0.01 & -1.85 & 0.077 \\
\hline T2 A vs $B$ & -0.30 & 0.7 & -0.4 & -0.15 & -4.12 & $0.00 * *$ \\
\hline T3 A vs B & -0.33 & 0.8 & -0.5 & -0.18 & -4.22 & $0.00 * *$ \\
\hline \multicolumn{7}{|l|}{ MMP-2 } \\
\hline T0 A vs B & -9.4 & 6.6 & -23.03 & 4.2 & -1.4 & 0.168 \\
\hline TI A vs $B$ & -42.2 & 15.8 & -74.8 & -9.6 & -2.7 & $0.013^{*}$ \\
\hline $\mathrm{T} 2 \mathrm{~A}$ vs $\mathrm{B}$ & -64.3 & 21.01 & -107.6 & -20.9 & -3.06 & $0.005 * *$ \\
\hline T3 $A$ vs $B$ & -33.3 & 16.3 & -66.9 & 0.36 & -2.04 & $0.049 *$ \\
\hline \multicolumn{7}{|l|}{ MMP-9 } \\
\hline T0 A vs B & 3.36 & 2.22 & -1.22 & 7.9 & 1.5 & 0.144 \\
\hline TI A vs $B$ & -20.56 & 5.6 & -32.07 & -9.05 & -3.7 & $0.001 * *$ \\
\hline T2 A vs B & -27.08 & 4.14 & -35.6 & -18.5 & -6.5 & $0.000 * *$ \\
\hline T3 $A$ vs $B$ & -18.16 & 3.5 & -25.4 & -10.9 & -5.19 & $0.000 * *$ \\
\hline \multicolumn{7}{|l|}{ NGAL } \\
\hline T0 A vs B & -6.36 & 3.06 & -12.69 & -0.02 & -2.073 & $0.049 *$ \\
\hline TI A vs B & -18.32 & 5.5 & -29.75 & -6.9 & -3.3 & $0.003 * *$ \\
\hline T2 A vs B & -64.16 & 5.12 & -74.7 & -53.5 & -12.5 & $0.000 * *$ \\
\hline T3 A vs B & -50.32 & 4.9 & -60.4 & -40.2 & -10.2 & $0.000 * *$ \\
\hline
\end{tabular}

Notes: T0: admission; TI: I month later; T2: 3 months later; T3: 6 months later. $* P<0.05 ; * * P<0.0$ I.

Abbreviations: $\mathrm{Cl}$, confidence interval of the difference; MMP, matrix metalloproteinase; NGAL, neutrophil gelatinase-associated lipocalin; SEM, standard error of the mean; $t$, paired samples $t$-test values. 


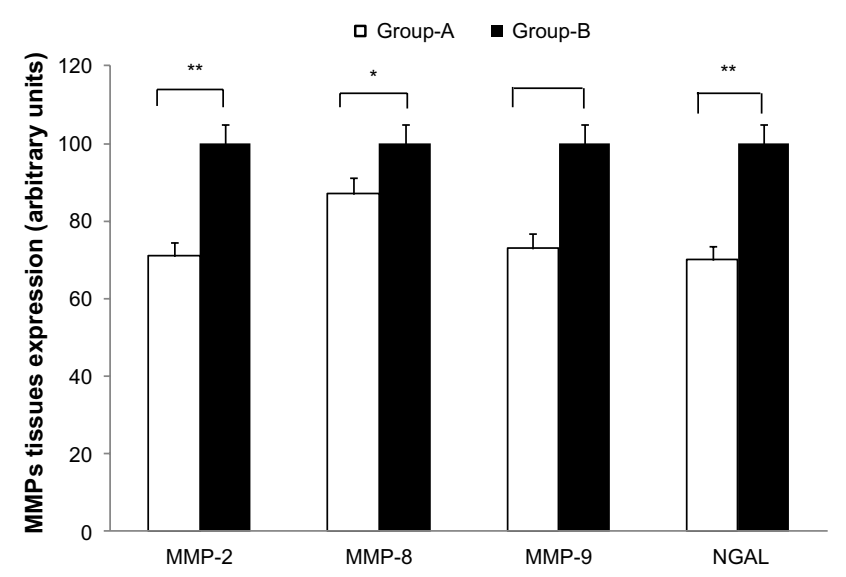

Figure I Western blot evaluation of MMPs and NGAL expression in wound tissues taken at the time of surgery in patients with CVUs treated (Group A) or not (Group B) with sulodexide at TI and T2 of the study.

Notes: Data are expressed as arbitrary units, where the higher value has been considered equal to 100. $* P<0.05 ; * * P<0.01$.

Abbreviations: CVU, chronic venous ulceration; NGAL, neutrophil gelatinaseassociated lipocalin; MMP, matrix metalloprotease.

glycosaminoglycans composed of low-molecular-weight heparin $(80 \%)$ and dermatan sulfate $(20 \%) .{ }^{57}$

Due to the concomitant presence of both fast-moving heparin, with affinity for antithrombin III, and dermatan sulfate, with affinity for heparin cofactor II (HCII), SDX shows lipidemic ( $>10 \mathrm{LRU} / \mathrm{mg})$, anticoagulant $(<100 \mathrm{IU} / \mathrm{mg})$, antiXa (70-100 IU/mg), HCII (<180 U/mg), Activated Partial Thromboplastin Time (APTT) ( $50 \mathrm{U} / \mathrm{mg})$, and antithrombotic effects. ${ }^{58}$
SDX, as well as heparin, may be able to inhibit leukocyte function and the release of elastase, ${ }^{59}$ moreover, SDX also shows in vitro and in vivo profibrinolytic actions. $^{28-32}$

SDX is useful in the treatment and secondary prevention of ischemic arterial cardiovascular events, ${ }^{56,60}$ deep vein thrombosis, ${ }^{61}$ and systemic and local inflammations. ${ }^{62}$ Moreover, Andreozzi ${ }^{30}$ reported that SDX treatment is associated with significant improvements in the clinical signs and symptoms of venous ulcers, while Coccheri et $\mathrm{al}^{55}$ documented in patients with venous leg ulcers that SDX associated with local treatment induced an improvement in ulcer healing without the development of side effects. In our study, we documented that SDX is able to reduce plasma and tissue levels of MMPs and NGAL. These effects may be related with the action of SDX on proteases that possess cysteine residues; we did, in fact, find that SDX has early effects on gelatinase (MMP-2 and MMP-9).

In this study, SDX treatment increased the healing of ulcers with an improvement in clinical symptoms and in quality of life of the enrolled patients. These effects showed a time-dependent pattern, with an initial improvement in the first month and with a complete remission within 3 months. During the follow-up at 6 months, we did not record any signs of wound disease and observed no side effects related to SDX treatment.

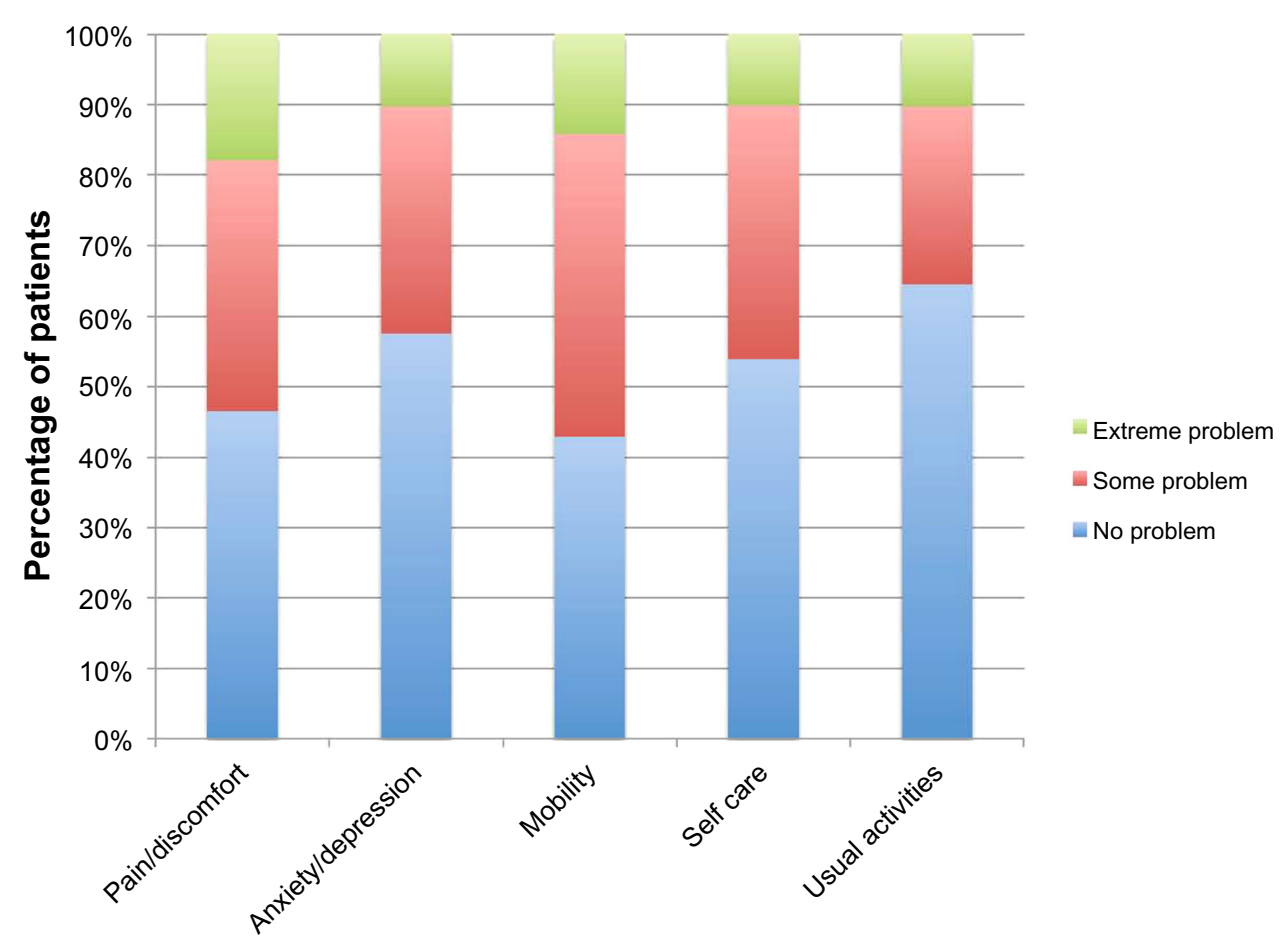

Figure 2 Results of qualify of life questionnaire in chronic venous ulceration patients treated with sulodexide for 6 months (at the end of the study) (Group A). 


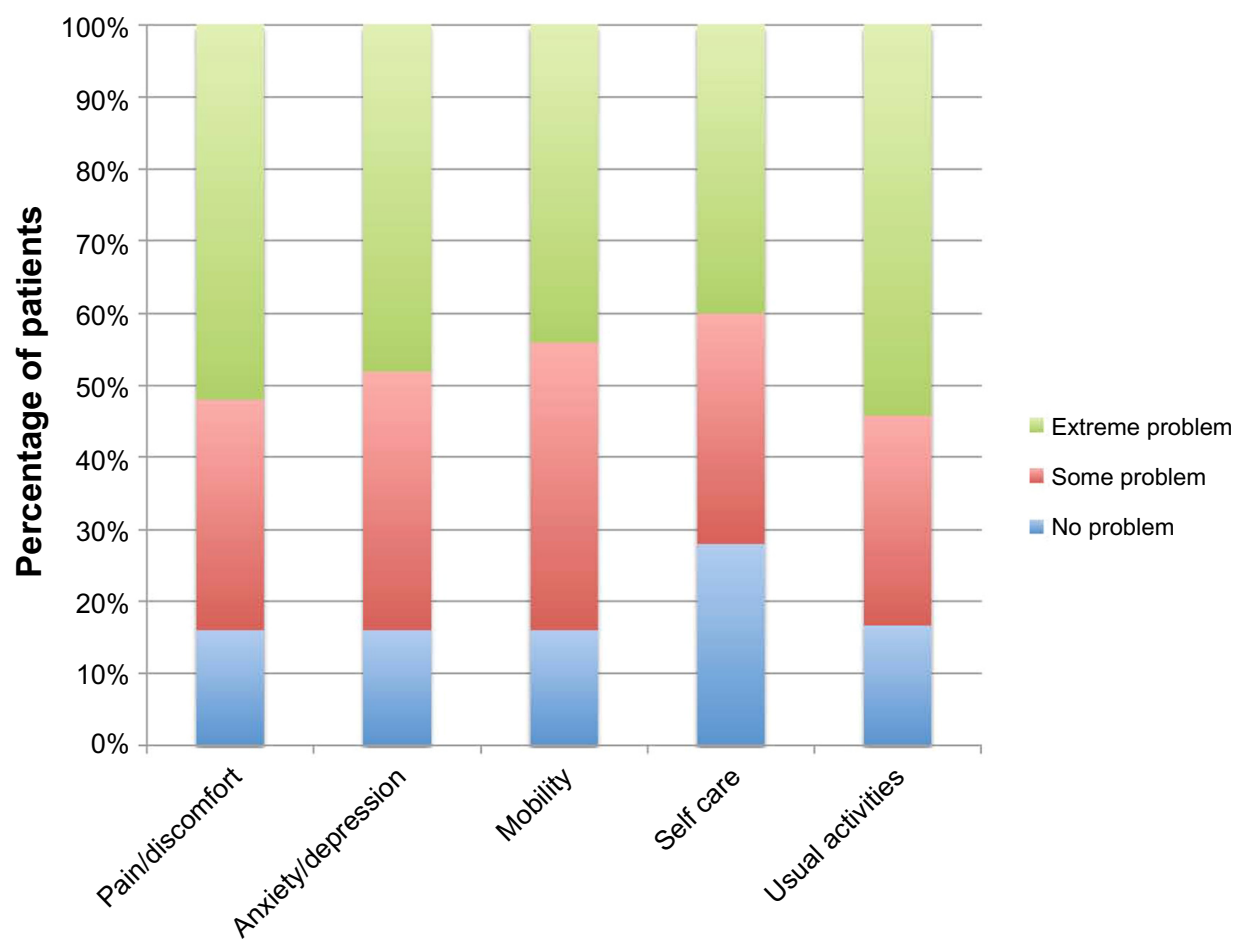

Figure 3 Results of qualify of life questionnaire in untreated chronic venous ulceration patients (at the end of the study) (Group B).

\section{Conclusion}

SDX represents a safe and efficacious treatment for patients with ulcers of mixed etiology; however, further studies are necessary to validate the observations presented here.

\section{Disclosure}

The authors report no conflicts of interest in this work.

\section{References}

1. Patton LR. Are community leg ulcer clinics more cost-effective than home care visits? J Wound Care. 2009;18(2):49-50, 52.

2. Hampton S. An introduction to various types of leg ulcers and their management. Br J Nurs. 2006;15(11):S9-S13.

3. Forssgren A, Fransson I, Nelzén O. Leg ulcer point prevalence can be decreased by broad-scale intervention: a follow-up cross-sectional study of a defined geographical population. Acta Derm Venereol. 2008;88(3):252-256.

4. Andersson E, Hansson C, Swanbeck G. Leg and foot ulcer prevalence and investigation of the peripheral arterial and venous circulation in a randomised elderly population. An epidemiological survey and clinical investigation. Acta Derm Venereol. 1993;73(1):57-61.

5. Apelqvist JA, Lepäntalo MJ. The ulcerated leg: when to revascularize. Diabetes Metab Res Rev. 2012;28 Suppl 1:30-35.

6. Serra R, Buffone G, de Franciscis A, et al. A genetic study of chronic venous insufficiency. Ann Vasc Surg. 2012;26(5):636-642.

7. Serra R, Grande R, Buffone G, Costanzo G, Damiano R, de Franciscis S. Chronic venous disease is more aggressive in patients with varicocele. Acta Phlebologica. 2013;14:57-60.

8. Serra R, Buffone G, Costanzo G, et al. Varicocele in younger as risk factor for inguinal hernia and for chronic venous disease in older: preliminary results of a prospective cohort study. Ann Vasc Surg. 2013;27(3):329-331.

9. Georgopoulos S, Kouvelos GN, Koutsoumpelis A, et al. The effect of revascularization procedures on healing of mixed arterial and venous leg ulcers. Int Angiol. 2013;32(4):368-374.
10. Lantis JC 2nd, Boone D, Lee L, Mendes D, Benvenisty A, Todd G. The effect of percutaneous intervention on wound healing in patients with mixed arterial venous disease. Ann Vasc Surg. 2011;25(1):79-86.

11. Ghauri AS, Nyamekye I, Grabs AJ, Farndon JR, Poskitt KR. The diagnosis and management of mixed arterial/venous leg ulcers in communitybased clinics. Eur J Vasc Endovasc Surg. 1998;16(4):350-355.

12. Nag F, De A, Hazra A, Chatterjee G, Ghosh A, Surana TV. Chronic venous ulceration of leg associated with peripheral arterial disease: an underappreciated entity in developing country. Int Wound J. Epub November 22, 2012.

13. Humphreys ML, Stewart AH, Gohel MS, Taylor M, Whyman MR, Poskitt KR. Management of mixed arterial and venous leg ulcers. Br J Surg. 2007;94(9):1104-1107.

14. Nagase H, Visse R, Murphy G. Structure and function of matrix metalloproteinases and TIMPs. Cardiovasc Res. 2006;69(3): $562-573$.

15. Serra R, Buffone G, Molinari V, et al. Low molecular weight heparin improves healing of chronic venous ulcers especially in the elderly. Int Wound J. Epub March 21, 2013.

16. de Franciscis S, De Sarro G, Longo P, et al. Hyperhomocysteinaemia and chronic venous ulcers. Int Wound J. Epub February 19, 2013.

17. Serra R, Buffone G, de Franciscis A, et al. Skin grafting followed by low-molecular-weight heparin long-term therapy in chronic venous leg ulcers. Ann Vasc Surg. 2012;26(2):190-197.

18. de Franciscis S, Grande R, Buffone G, Serra R. Chronic venous ulceration of the lower limbs and thrombosis. Acta Phlebologica. In press.

19. Gasbarro V, Amato B, Izzo M, et al. Quercetin and chronic venous ulceration of the lower limbs. Acta Phlebologica. 2013;14:61-65.

20. Serra R, Buffone G, Falcone D, et al. Chronic venous leg ulcers are associated with high levels of metalloproteinases- 9 and neutrophil gelatinaseassociated lipocalin. Wound Repair Regen. 2013;21(3):395-401.

21. Serra R, Grande R, Buffone G, Gallelli L, de Franciscis S. The effects of minocycline on extracellular matrix in patients with chronic venous leg ulcers. Acta Phlebologica. 2013;14(3):99-107.

22. Amato B, Coretti G, Compagna R, et al. Role of matrix metalloproteinases in non-healing ulcers. Int Wound J. Epub October 24, 2013. 
23. de Franciscis S, Mastroroberto P, Gallelli L, Buffone G, Montemurro R, Serra R. Increased plasma levels of metalloproteinase- 9 and neutrophil gelatinase-associated lipocalin in a rare case of multiple artery aneurysm. Ann Vasc Surg. 2013;27(8):1185. e5-e7.

24. de Franciscis S, Gallelli L, Battaglia L, et al. Cilostazol prevents foot ulcers in diabetic patients with peripheral vascular disease. Int Wound $J$. Epub May 15, 2013.

25. Busceti MT, Grande R, Amato B, et al. Pulmonary embolism, metalloproteinases and neutrophil gelatinase associated lipocalin. Acta Phlebologica. 2013;14(3):115-121.

26. Serra R, Buffone G, Costanzo G, et al. Altered metalloproteinase- 9 expression as least common denominator between varicocele, inguinal hernia, and chronic venous disorders. Ann Vasc Surg. 2014;28(3): 705-709.

27. Malemud CJ. Matrix metalloproteinases (MMPs) in health and disease: an overview. Front Biosci. 2006;11:1696-1701.

28. Voigt J, Driver VR. Hyaluronic acid derivatives and their healing effect on burns, epithelial surgical wounds, and chronic wounds: a systematic review and meta-analysis of randomized controlled trials. Wound Repair Regen. 2012;20(3):317-331.

29. Humbert P, Mikosinki J, Benchikhi H, Allaert FA. Efficacy and safety of a gauze pad containing hyaluronic acid in treatment of leg ulcers of venous or mixed origin: a double-blind, randomised, controlled trial. Int Wound J. 2013;10(2):159-166.

30. Andreozzi GM. Sulodexide in the treatment of chronic venous disease. Am J Cardiovasc Drugs. 2012;12(2):73-81.

31. Lauver DA, Lucchesi BR. Sulodexide: a renewed interest in this glycosaminoglycan. Cardiovasc Drug Rev. 2006;24(3-4):214-226.

32. Mannello F, Medda V, Ligi D, Raffetto JD. Glycosaminoglycan sulodexide inhibition of MMP-9 gelatinase secretion and activity: possible pharmacological role against collagen degradation in vascular chronic diseases. Curr Vasc Pharmacol. 2013;11(3):354-365.

33. Yung S, Chau MK, Zhang Q, Zhang CZ, Chan TM. Sulodexide decreases albuminuria and regulates matrix protein accumulation in C57BL/6 mice with streptozotocin-induced type I diabetic nephropathy. PLoS One. 2013;8(1):e54501.

34. Lewis EJ, Lewis JB, Greene T, et al; Collaborative Study Group. Sulodexide for kidney protection in type 2 diabetes patients with microalbuminuria: a randomized controlled trial. Am J Kidney Dis. 2011;58(5):729-736.

35. Eklöf B, Rutherford RB, Bergan JJ, et al; American Venous Forum International Ad Hoc Committee for Revision of the CEAP Classification. Revision of the CEAP classification for chronic venous disorders: consensus statement. J Vasc Surg. 2004;40(6):1248-1252.

36. Fragomeni G, Merola A, Serra R, de Franciscis S, Amato F. A nonlinear lumped parameters model to analyze the dynamics of venous reflux. Conf Proc IEEE Eng Med Biol Soc. 2008;2008:1407-1410.

37. de Franciscis S, Gasbarro V, Amato B, Buffone G, Grande R, Serra R. Hemodynamic surgery versus conventional surgery in chronic venous disease: a multicenter retrospective study. Acta Phlebologica. 2013;14(3):109-114.

38. Al-Qaisi M, Nott DM, King DH, Kaddoura S. Ankle brachial pressure index (ABPI): An update for practitioners. Vasc Health Risk Manag. 2009;5:833-841.

39. Rabin R, de Charro F. EQ-5D: a measure of health status from the EuroQol Group. Ann Med. 2001;33(5):337-343.

40. Obradovic M, Lal A, Liedgens H. Validity and responsiveness of EuroQol-5 dimension (EQ-5D) versus Short Form-6 dimension (SF-6D) questionnaire in chronic pain. Health Qual Life Outcomes. 2013;11:110.

41. Pina E, Furtado K, Franks PJ, Moffatt CJ. [Leg ulcers in Portugal: an underestimated health care problem]. Rev Port Cir Cardiotorac Vasc. 2004;11(4):217-221. Portuguese.

42. Finlayson K, Edwards H, Courtney M. Relationships between preventive activities, psychosocial factors and recurrence of venous leg ulcers: a prospective study. J Adv Nurs. 2011;67(10):2180-2190.
43. Moffatt CJ, Franks PJ, Doherty DC, Martin R, Blewett R, Ross F. Prevalence of leg ulceration in a London population. QJM. 2004;97(7): 431-437.

44. Baker SR, Stacey MC, Singh G, Hoskin SE, Thompson PJ. Aetiology of chronic leg ulcers. Eur J Vasc Surg. 1992;6(3):245-251.

45. Nelzén O, Fransson I. True long-term healing and recurrence of venous leg ulcers following SEPS combined with superficial venous surgery: a prospective study. Eur J Vasc Endovasc Surg. 2007;34(5): 605-612.

46. Fletcher A, Cullum N, Sheldon TA. A systematic review of compression treatment for venous leg ulcers. BMJ. 1997;315(7108):576-580.

47. Dean S. Leg ulcers - causes and management. Aust Fam Physician. 2006;35(7):480-484.

48. Siniscalchi A, Gallelli L, Malferrari G, Pirritano D, Serra R, Santangelo E, De Sarro G. Cerebral stroke injury: the role of cytokines and brain inflammation. J Basic Clin Physiol Pharmacol. 2014;25(2):131-137.

49. Kucukguven A, Khalil RA. Matrix metalloproteinases as potential targets in the venous dilation associated with varicose veins. Curr Drug Targets. 2013;14(3):287-324.

50. Raffetto JD. Inflammation in chronic venous ulcers. Phlebology. 2013;28 Suppl 1:61-67.

51. Serra R, Gallelli L, Buffone G, et al. Doxycycline speeds up healing of chronic venous ulcers. Int Wound J. Epub April 5, 2013.

52. Trengove NJ, Stacey MC, MacAuley S, et al. Analysis of the acute and chronic wound environments: the role of proteases and their inhibitors. Wound Repair Regen. 1999;7(6):442-452.

53. Serra R, Grande R, Butrico L, et al. Effects of a new nutraceutical substance on clinical and molecular parameters in patients with chronic venous ulceration. Int Wound J. Epub February 25, 2014.

54. Serra R, Grande R, Gallelli L, Rende P, Scarcello E, Buffone G, et al. Carotid body paragangliomas and Matrix Metalloproteinases. Ann Vasc Surg. Epub April 2, 2014.

55. Coccheri S, Scondotto G, Agnelli G, Aloisi D, Palazzini E, Zamboni V; Venous arm of the SUAVIS (Sulodexide Arterial Venous Italian Study) Group. Randomised, double blind, multicentre, placebo controlled study of Sulodexide in the treatment of venous leg ulcers. Thromb Haemost. 2002;87(6):947-952.

56. Condorelli M, Chiariello M, Dagianti A, et al. IPO-V2: a prospective, multicenter, randomized, comparative clinical investigation of the effects of sulodexide in preventing cardiovascular accidents in the first year after acute myocardial infarction. $J$ Am Coll Cardiol. 1994;23(1):27-34.

57. Harenberg J. Review of pharmacodynamics, pharmacokinetics, and therapeutic properties of sulodexide. Med Res Rev. 1998;18(1):1-20.

58. Verstraete M, Zoldhelyi P. Novel antithrombotic drugs in development. Drugs. 1995;49(6):856-884.

59. Redini F1, Tixier JM, Petitou M, Choay J, Robert L, Hornebeck $\mathrm{W}$. Inhibition of leucocyte elastase by heparin and its derivatives. Biochem J. 1988;252(2):515-519.

60. Cosmi B, Cini M, Legnani C, Pancani C, Calanni F, Coccheri S. Additive thrombin inhibition by fast moving heparin and dermatan sulfate explains the anticoagulant effect of sulodexide, a natural mixture of glycosaminoglycans. Thromb Res. 2003;109(5-6):333-339.

61. Cirujeda JL, Granado PC. A study on the safety, efficacy, and efficiency of Sulodexide compared with acenocoumarol in secondary prophylaxis in patients with deep venous thrombosis. Angiology. 2006;57(1):53-64.

62. Ciszewicz M, Polubinska A, Antoniewicz A, Suminska-Jasinska K, Breborowicz A. Sulodexide suppresses inflammation in human endothelial cells and prevents glucose cytotoxicity. Transl Res. 2009;153(3):118-123. 
Drug Design, Development and Therapy

Dovepress

\section{Publish your work in this journal}

Drug Design, Development and Therapy is an international, peerreviewed open-access journal that spans the spectrum of drug design and development through to clinical applications. Clinical outcomes, patient safety, and programs for the development and effective, safe, and sustained use of medicines are a feature of the journal, which

has also been accepted for indexing on PubMed Central. The manuscript management system is completely online and includes a very quick and fair peer-review system, which is all easy to use. Visit $\mathrm{http}: / / \mathrm{www}$.dovepress.com/testimonials.php to read real quotes from published authors.

Submit your manuscript here: http://www.dovepress.com/drug-design-development-and-therapy-journal 